and animals with diabetes insipidus, and Dr. Lucie Arvy (Paris) showed slides which gave the first suggestion that the neurohypophysis is implicated in the osmoregulation of teleost fishes.

The pleasant atmosphere and the apparently general enjoyment in the symposium can be attributed not only to the restricted number of participants (nearly all of whom were actively engaged in research on its subject) but also to the excellent arrangements of the Colston Research Society, which housed all members in Manor Hall, a hall of residence of the University of Bristol. The scientific meetings were held in the same building, so that much unnecessary inconvenience and loss of time were avoided. The proceedings of the symposium will be published as Volume 8 of the "Colston Papers". H. HeLler

\section{EUROPEAN SEISMOLOGICAL COMMISSION \\ MEETINGS IN VIENNA}

T

HE European Seismological Commission, a Commission set up by the Section for Seismology and the Physics of the Interior of the Earth of the International Union of Geodesy and Geophysics, met in the Institute of Physics of the University of Vienna during April 4-7 under the presidency of Prof. W. Hiller, of Stuttgart. The Commission had the support of Unesco, and nineteen countries were represented. Four topics were discussed : the organization and preparation for carrying out large explosions, particularly in Alpine regions, for seismic purposes; the progress achieved in the preparation of a European Earthquake Catalogue and a seismotectonic map of Europe; the progress made in the design and construction of seismographs, particularly those to be used to record near earthquakes, and the testing of such instruments; and microseisms.

The methods of seismic prospecting for minerals (particularly for possible oil-bearing structures) by letting off small quantities of explosives and receiving the reflected and refracted sound waves on geophones or seismographs are by now well known, and the subject has an extensive literature of its own. It was by this means that the British oilfield at Eakring was discovered. Only one explosion in Great Britain has been large enough to send waves down to penetrate all the layers of the Earth's crust, and this explosion was accidental-namely, the Burton-onTrent explosion of November 27, 1944. In 1909 A. Mohorovičic found a discontinuity at the base of the continental layers of the Earth's crust in south-east Europe at a depth of $60 \mathrm{~km}$., now called the Mohorovičić discontinuity. Its depth varies over the Earth, but it is almost always present ; in France it is estimated to be at a depth of $38 \mathrm{~km}$., and under the Central Appalachians in the United States it is $40-50 \mathrm{~km}$. The possible variation of the depth of the Mohorovičic discontinuity under mountain regions such as the Alps in Europe is particularly interesting, and it is proposed to try to find such depths by using the methods of seismic prospecting with sufficient quantities of explosives so that the $P$-waves which are generated will penetrate below the discontinuity. The time and place of the explosion, being known, will give fewer unknowns in the calculations than with natural earthquakes, and the arrival times of the reflected and refracted waves, being approx- imately known, will render possible the use of faster than normal paper speeds in the seismographs and thus greater accuracy in the time measurement. Moreover, since the explosion point is known, it will be possible to arrange the positions of the seismographs to advantage both in azimuth and distance.

The first experiments in western Europe will be carried out by the French during the second half of August 1956 at Briancon. The first explosions will be set off in the middle of a lake which is situated at a height of $2,500 \mathrm{~m}$. above sea-level, and there will be five successive explosions of $1,2,2,5$ and 10 tonnes. The first ones will give experience of the best methods, and the whole series will give an idea of the optimum or minimum quantity of explosive necessary for the purpose. The French will set up seismographs situated along two lines which will intersect at right angles at the lake. The explosions will also be recorded by seismographs in Germany, Italy and perhaps in Czechoslovakia. As soon as the results of this work have been studied, the French seismologists propose to make a further series of similar experiments from a lake situated $40-50 \mathrm{~km}$. to the east of the first one, so that records may be obtained over the same ground but in the reverse direction. This is so that true wave velocities may be determined in the manner usual in seismic prospecting. The second series of explosions will probably be held in 1957. As soon as the results of the first French experiments are known, similar explosion experiments will be made in the Eastern Alps, probably in the Hohe Tauern, east of Innsbruck in Austria, but these will not be possible this year.

Experiments in the U.S.S.R. along these lines have already taken place, organized by the Geophysical Institute of the U.S.S.R. Academy of Sciences under Academician G. A. Gamburtzev, the results being communicated to the Vienna meeting by Prof. E. F. Savarensky. The method used by the Russians is called the GSZ method and makes use of explosions of 50-300 kgm. of material. The distance between the explosion point and reception point may be up to $400 \mathrm{~km}$. The charges are usually placed in reservoirs, lakes or rivers and are exploded during meteorologically quiet times at night. The effective sensitivity of the reception devices is increased by properly regulated frequency ranges with a maximum amplification, by the increase of the general sensitivity of the equipment under a low level of internal noise and by use of methods of bunching reception. The registration of waves, including radiation of wavelength shorter than usually recorded hitherto, is effected by the use of many-channel stations which permits the most effective correlation methods. Receptors are arranged in different azimuths, and note is taken of the polarization of the oscillations. Different types of waves are distinguished (longitudinal, transverse and surface), as are also differences between single waves and waves resulting from complex interference. Separate crossings of profiles and also groups of reception points are used, the shot point being static.

In particular, large explosions have been made by these methods and for these purposes at Korkino near Chelyabinsk in the Ural Mountains, at Tula in the European part of the U.S.S.R. and in Central Asia. The GSZ method was used in pre-mountain and mountain regions of North Tien-Shan, in Western Turkmenia, in Pamiro-Altaisk and other regions. The section from south to north through the moun. tain ridges of the Kungey-Ala-Tau and Jan Karsky- 
Ala-Tau shows two roots going deep into the Mohorovičic discontinuity. The granitic layer shows no roots, but the Mohorovičic discontinuity repeats, with some distortions and with greater amplitudes, the surface relief. It is noteworthy that the foci of all natural earthquakes in the district originate near the basaltic layer, and that the large negative gravity anomaly (up to $250 \mathrm{mgl}$.) in the district depends mainly on the form of the Mohorovičce discontinuity and not on the granitic layer. The GSZ method of deep seismic sounding has thus been used in the U.S.S.R. to study the peculiarities of relief of the internal crustal layers of the Earth (sedimentary, granitic, basaltic), especially in mountain regions; to study these surfaces near deep geological faults; and to give a quantitative physical explanation of the peculiarities of the regional gravitational field. At the Vienna meeting E. Tillotson described the work of Dr. M. N. Hill, of Cambridge, and his coworkers, who use explosions at sea in order to determine the structure of the sea bed. In this method use is made of sono-radio buoys. Prof. $\mathrm{H}$. Menzel and his colleagues at Hamburg intend to follow this method in order to elucidate the very interesting geological structures between Germany and Denmark on one hand, and Norway and Sweden on the other.

Reports from countries represented at the meeting, and also twelve papers, were read concerning the proposed seismo-tectonic map of Europe and the making of the European Earthquake Catalogue. This project is now locally well advanced, and the collection and correlation of the data were placed in the hands of Dr. M. Båth, of Upsala, with the assistance of six colleagues strategically placed in Europe. It is intended, when the map has been completed, to shade it to show the different degrees of seismicity.

Six papers were read at the Vienna meeting, and a good deal of discussion took place, concerning short-period seismographs for the registration of near earthquakes. One paper, presented by Prof. W. Hiller, concerned the new short-period seismographs with magnetic amplification for recording on smoked paper, the prototypes of which have been set up in Stuttgart. The European Seismological Commission recommended the standardization of the constants of short-period electromagnetic seismographs so far as local circumstances permit. Each instrument should have a period $\left(T_{m}\right)$ of the movement of the ground corresponding to a maximum sensitivity between 0.6 and 1.0 sec., and damping coefficients $\alpha$ and $\beta$ of the pendulum and galvanometer for the seismograph without equivalent reaction, greater than or equal to $0 \cdot 6$. It was left to a small committee under Prof. F. Gassman, of Zurich, to investigate the best methods of testing short-period instruments by shaking-table experiments.

Three papers on microseisms were read, and the Commission passed a resolution requesting the Seismological Commission of the International Geophysical Year to give as soon as possible all the necessary directives for making as complete an investigation as possible of microseismic activity during the International Geophysical Year. Prof. K. E. Bullen, of Sydney, president of the Section of Seismology and the Physies of the Earth's Interior, then gave a lecture on his present tentative views concerning the structure of the Earth with its mantle, core and inner core, and the structure of some of the planets.
Additional members of the European Seismological Commission were then agreed upon from Czechoslovakia, Lebanon, Poland, Rumania, Switzerland (in place of Dr. Wanner, deceased) and the U.S.S.R. Officers elected were: President, Prof. P. Caloi (Rome) ; Vice-President, Prof. W. Hiller (Stuttgart); and Secretary, Elie Peterschmitt (Strasbourg). The next meeting of the Commission will be held in Utrecht during Whitsuntide 1958.

ERnest Tillotson

\section{RADIO-FREQUENCY PHYSICS}

\section{CONFERENCE IN GENEVA}

$T$

HE 'Colloque A.M.P.E.R.E.' (Atomes et Molécules par Etudes Radio-Electriques) is an organization inspired by Prof. R. Freymann, of the University of Rennes, which was set up soon after the end of the Second World War as a means of ensuring fruitful contact between French research workers interested in any branch of physics that is concerned with the use of radio frequencies (including the microwave region). It was also part of an effort to re-establish scientific research in France, which had suffered very heavily in the War and was quite unfamiliar with the great advances made during the years of hostilities. The subjects at the annual conferences include dielectric constant and loss, magnetic permeability and loss, nuclear mag. netic resonance, quadrupole magnetic resonance, paramagnetic resonance, ferromagnetic resonance and associated effects, and microwave spectroscopy. Although primarily a French organization, interest in it has become more general, and it would now be better described as European, although, of course, any scientist is welcome. It has been a matter of considerable pride and satisfaction to the Frenchspeaking members that all the conferences have employed French as the principal language. I feel that this-and the colloquium itself-has helped to give the French renewed confidence and has contributed in some measure to the present renaissance of scientific research in France. It has also made many English-speaking persons appreciate the difficulties which the prevalent use of English at scientific conferences poses for many scientists.

A pattern is being established in which the annual conference is held alternately in France and elsewhere in Europe. This year's conference was held during March 21-23 in the Institute of Physics of the University of Geneva and was attended by some hundred and fifty scientific workers. That for 1957 will be held in St. Malo, Brittany, and will be organized by Prof. R. Freymann.

A special effort was made to widen the appeal of the conference this year in view of the fact that it marks the tenth anniversary of the discovery of nuclear magnetic resonance absorption. General lectures outlining the history and present situation in nuclear magnetic resonance were given by Prof. C. J. Gorter (Leyden), "Vingt années de recherches aux Pays-Bas sur les résonances magnétiques"; Prof. M. Grivet (Paris), "Exposé sur les travaux effectués par l'équipe française de résonance nucléaire" ; Prof. L. Giulotto (Pavia), "Exposé sur les travaux récents effectués au Laboratoire de Pavie dans le domaine des temps de relaxation nucléaire"; Prof. R. A. Ogg (Stanford), "Application à la chimie 